\title{
LA REGIÓN PAMPEANA COMO UNIDAD ESPACIAL DE ANÁLISIS EN LA ARQUEOLOGÍA CONTEMPORÁNEA
}

\author{
Gustavo Politis y Paula Barros
}

\section{Introducción}

En este artículo se discutirá la región pampeana como una unidad espacial y cultural del análisis arqueológico y se analizará la validez y la operatividad que mantiene actualmente. Desde el inicio de la arqueología en Argentina, esta región fue usada como unidad de análisis, pero fue definida con diferentes criterios y grados de resolución (e.g., Lehmann-Nitsche 1910, Willey 1944, Madrazo 1973, Politis 1984). Fundamentalmente, se utilizaron criterios fisiográficos y ecológicos, combinados de manera diversa con criterios culturales, tanto arqueológicos como históricos y etnográficos.

En este trabajo se examinarán los criterios utilizados para considerar a la región pampeana como una unidad de análisis. Esto es significativo ya que el uso de información tanto ecológica como cultural, provocó ciertas incongruencias en la forma en que se ha hecho operativo el establecimiento y la definición de los límites de la región pampeana. De alguna manera esto ha permeado múltiples aspectos de la investigación arqueológica, desde el recorte geográfico de los temas hasta el agrupamiento de ponencias en los congresos o la organización de las exhibiciones en los museos.

\section{Antecedentes}

A fines del siglo XIX hubo un cambio significativo en la manera de enfocar la discusión sobre los aborígenes que habitaron el territorio argentino. El problema se desplazó de la discusión de la antigüedad hacia la cuestión de la distribución espacial de la cultura material (Podgorny 1999). Este cambio estuvo motivado, entre otras cosas, por la necesidad de organizar los materiales arqueológicos en los nuevos museos que se estaban creando en ese entonces. Hasta 1908 la discusión de los restos arqueológicos se centraba de una manera u otra en el tema de la antigüedad (Podgorny 1999). En gran parte este debate en la región pampeana lo había originado Florentino Ameghino (1880), con su postulación del origen americano (más específicamente pampeano-patagónico) de la humanidad. En esa época, Ameghino se refería a una región vagamente definida a la que denominó "el Plata". Sin embargo, a partir de 1908 se generó una alternativa nueva para la organización de los pueblos indígenas, tanto del pasado como del presente: la combinación entre la división temporal y la geográfica (Podgorny 1994).

Originalmente Moreno había dividido al territorio argentino en regiones, y sobre éstas se basó la organización del Museo de La Plata. Lo que actualmente, con cierto consenso, se define como región pampeana, para Moreno estaba repartido en varias unidades espaciales: región pampeana, Buenos Aires, Pampa Central y parte de San Luis (Podgorny 
1999). Posteriormente, los diferentes directores del Museo de La Plata eligieron el sistema de clasificación de Delachaux (1908) porque respetaba para cada región la integridad política de las provincias. En este sistema, seguido por Lehmamn-Nitsche para clasificar el territorio argentino y organizar las exhibiciones, la actual región pampeana era parte integrante de dos regiones y de varias secciones: región litoral u oriental (la cual en su sección "C" incluía las provincias de Santa Fé y de Buenos Aires) y la región mediterránea o central (que incluía las provincias de Córdoba, San Luis y la gobernación de La Pampa).

En 1910 se introduce un nuevo elemento en la definición de las unidades espaciales. En ese año, Outes y Bruch (1910) publican su libro Los aborigenes argentinos y organizan el material arqueológico basándose en unidades temporales tomadas de la prehistoria europea: paleolítico, neolítico y edad de bronce. Sin embargo, los pueblos indígenas históricos son agrupados en "provincias geoétnicas" y así descritos mediante varios rasgos asociados. Este nuevo concepto es utilizado luego por Torres (1917) quien agrupa series culturales para cada región física del país (Podgorny 1999). En una re-edición y ampliación del trabajo original, Torres (1935) modifica el mapa de $1917 \mathrm{y}$ define "las cuatro regiones naturales del territorio argentino", una de las cuales incluye lo que hoy definimos como región pampeana.

Durante este período, se consideraba a la región pampeana, y a los indígenas que habían vivido en ella, como una unidad con pocas variaciones internas. Sin embargo hay dos antecedentes importantes para la identificación de diferencias significativas dentro de la región. Uno es el de Gordon Willey (1944) quién propuso varias áreas dentro de esta región, aunque incluyó algunas que en aquel entonces y ahora no se considerarían "pampeanas" (por ejemplo la "III" que incluía casi toda la pcia. de Mendoza y Neuquen). El otro trabajo importante es el de Madrazo $(1973,1979)$ quien identificó diferencias fisiográficas, y para él claramente culturales, dentro de la región y propuso la existencia de "aspectos" y "focos". Estas dos categorías fueron imperfectamente definidas (sobre todo porque se basaron en diferentes criterios) y poco operativas, aun así, capturaron a alguna escala las diferencias intra- regionales.

Hasta la década de 1980 prevaleció la idea de región pampeana como una gran área cultural relativamente homogénea (e.g., Menghín y Bórmida 1950). Por ejemplo, siguiendo esta idea, muy arraigada en aquel entonces, Austral (1971) expreso que:

"Este panorama formulado en base a la arqueología de la Pampa bonaerense (subregión pampeana húmeda) se extiende tentativamente a toda la región pampeana, en la que la ausencia de vallas naturales de importancia hace presumir un desarrollo cultural en términos generales semejantes" (Austral 1971:64).

También en su obra de síntesis de la arqueología argentina, Jorge Fernández se refirió a las áreas del territorio argentino. En principio aclaró que la mejor definida en términos operativos es el área Andina Meridional (definida por González y Pérez 1966). Con respecto a las otras áreas expresa que:

"la mayoría de los autores hacen referencia a las grandes áreas geoculturales Chaco-Litoral (Nordeste) y Pampa-Patagonia, que 
incluye Tierra del Fuego, las que sin duda deberán ser en el futuro objeto de divisiones más exactas" (Fernández 1982).

Ya en la década de los 80 Politis (1984) formalizó las diferencias internas de la región y definió siete áreas dentro de la subregión pampa-húmeda: Norte, Depresión del Río Salado, Oeste, Tandilia, Ventania, Interserrana y Sur. En términos ecológicos y fisiográficos, esta propuesta se basó en los trabajos geográficos clásicos de Daus (1968, 1969) y en los aportes de la geología (Rolleri 1975). Posteriormente, y siguiendo criterios similares, se dividió también la sub-región Pampa-Seca en cuatro áreas: Bajos sin Salida, Meseta Basáltica, Caldenar y Salado-Chadileuvú-Curacó (Berón y Politis 1997). En ambos casos, la diferenciación de áreas estaba fundada principalmente en los rasgos fisiográficos, aunque se consideró también, de manera complementaria, el registro arqueológico de cada una de ellas. Sin embargo, estas diferencias en el registro no fueron atribuidas a distinciones culturales y de hecho se propuso que era posible que las mismas sociedades ocuparan diferentes áreas y que dejaran registros diversos en función de los recursos explotados, de la tecnología usada y del tipo de asentamiento (esto fue específicamente discutido para las diferencias entre las áreas Interserrana y Tandilia, véase Politis 1984). En consecuencia se podría concluir que las áreas definidas por Politis primero y por Berón y Politis después se basaron primeramente en criterios fisiográficos y secundariamente arqueológicos (Fig. 1). Por lo tanto, en estos términos, la región pampeana no es asignable a un "área cultural" en el sentido clásico del concepto (e.g., Steward 1955), aunque hayan intervenido rasgos arqueológicos en su definición.

Aunque luego hubo algunas excepciones (e.g.; Orquera 1987) la mayoría de los autores que trabajaron en la región consideraron estas diferencias como unidades espaciales de análisis, lo que se refleja en los trabajos de síntesis regionales o de áreas (Mazzanti 1993, Martínez 1999, Politis y Madrid 2001, Bonomo 2004, Martínez y Gutiérrez 2004, González de Bonaveri 2005, entre otros). De esta manera, por uso y no por un acuerdo explícito, la región pampeana y las áreas propuestas dentro de ellas, se transformaron en unidades espaciales de análisis operativas y relativamente consensuadas entre los arqueólogos que investigan en la región.

\section{Las bases ecológicas de la región pampeana}

La región pampeana es definida genéricamente como una llanura con pastizales que ocupa el este de la Argentina entre $\operatorname{los} 30^{\circ}$ y $39^{\circ}$ de latitud Sur, el Uruguay y la mitad austral del estado de Río Grande do Sul, en Brasil. Sin embargo, según los criterios ecológicos que se usen para definirla existen diferencias sustanciales (véanse por ejemplo Frenguelli 1940, Parodi 1947, De Aparicio y Difrieri 1958, Daus 1968, Soriano et al. 1992). Los rasgos del relieve y del clima sirvieron como fundamento de la definición inicial de la región pampeana como una entidad fisiográfica, representada por una planicie sin árboles, de clima templado, sin estación seca marcada y cubierta por una alfombra de gramíneas durante todo el año (Daus 1968). Esta planicie posee una suave pendiente hacia el Este- 
Sudeste y su horizontalidad se interrumpe sólo por los relieves incluídos en los sistemas de Ventania y Tandilia en la pampa oriental y el de Mahuidas en la occidental.

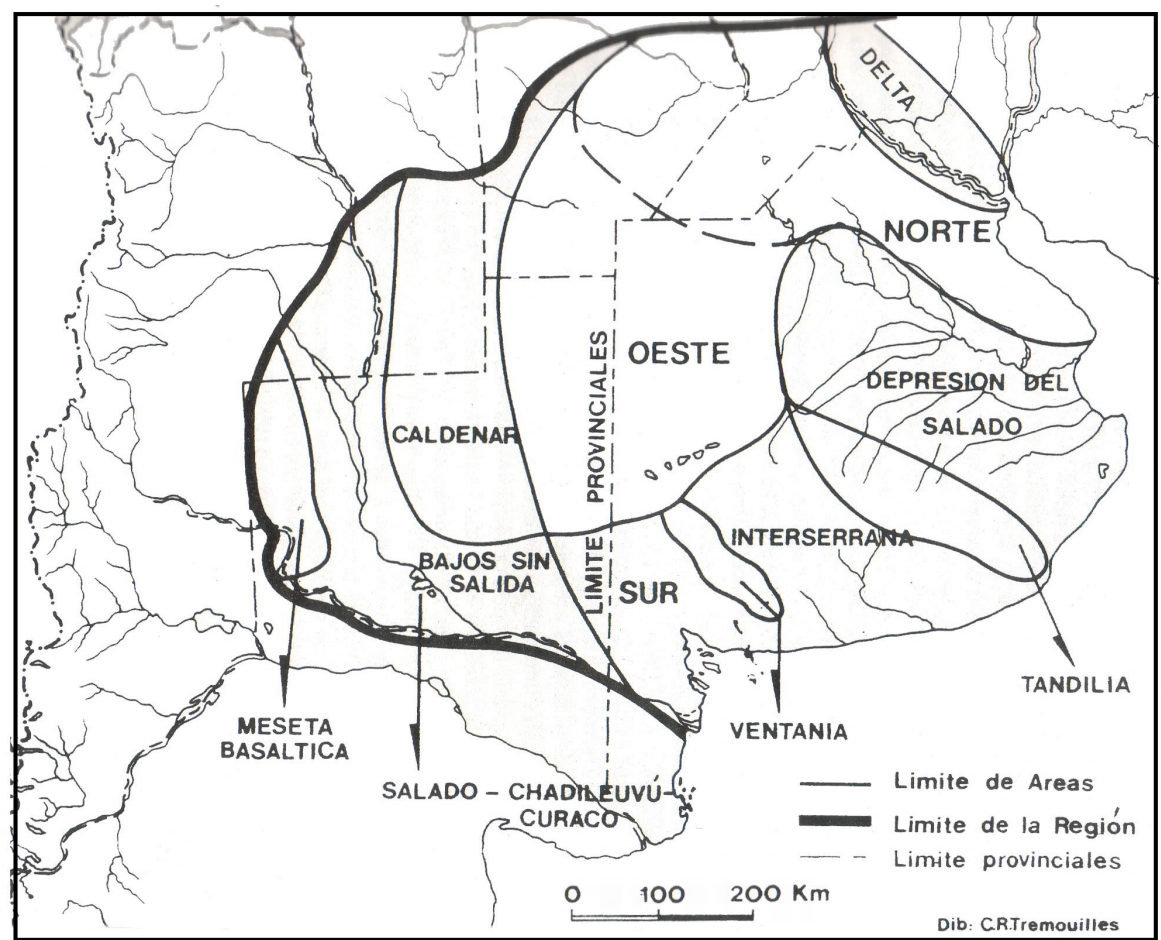

Fig. 1. La región Pampeana y sus areas. Tomado de Berón y Politis (1997)

Otro sector diferenciado de la Pampa es la llanura que está al Oeste del eje fluvial Paraná-Plata. En cuanto a su topografía, esta área se individualiza por ondulaciones debidas a reiterados ciclos de erosión fluvial. La cuenca del Río Salado forma una banda deprimida y presenta numerosas lagunas, ciertas de ellas están encadenadas, como el de Mar Chiquita que en el curso superior del río se dilata hasta la provincia de Santa Fe y el de ChascomúsPila, en el curso inferior. También se manifiesta en este sector occidental de la Pampa la presencia de un elemento topográfico particular, que son lomadas formadas por médanos fijados por la vegetación (Daus 1968).

Desde el punto de vista fitogeográfico, la región Pampeana pertenece al dominio chaqueño de la región Neotropical (Cabrera 1980) (Fig. 2). Además de los trabajos clásicos (Frenguelli 1940, Parodi 1947), las dos contribuciones mas usadas que han definido los pastizales pampeanos y sus distritos son la de Cabrera (1980) y la de Soriano et al (1992). El primero distingue cuatro distritos: Uruguayense: (Sur de Brasil; Uruguay, Entre Ríos y Santa Fé), Pampeano Oriental: (desde el Norte y Este de la provincia de Buenos Aires, hasta las serranías de Tandil y Balcarce), Pampeano Occidental: (Sur de Córdoba; el Nordeste de 
Folia Histórica del Nordeste, $\mathbf{N}^{\circ} 16$ (Resistencia, 2006) IIGHI, CONICET - IH, UNNE)

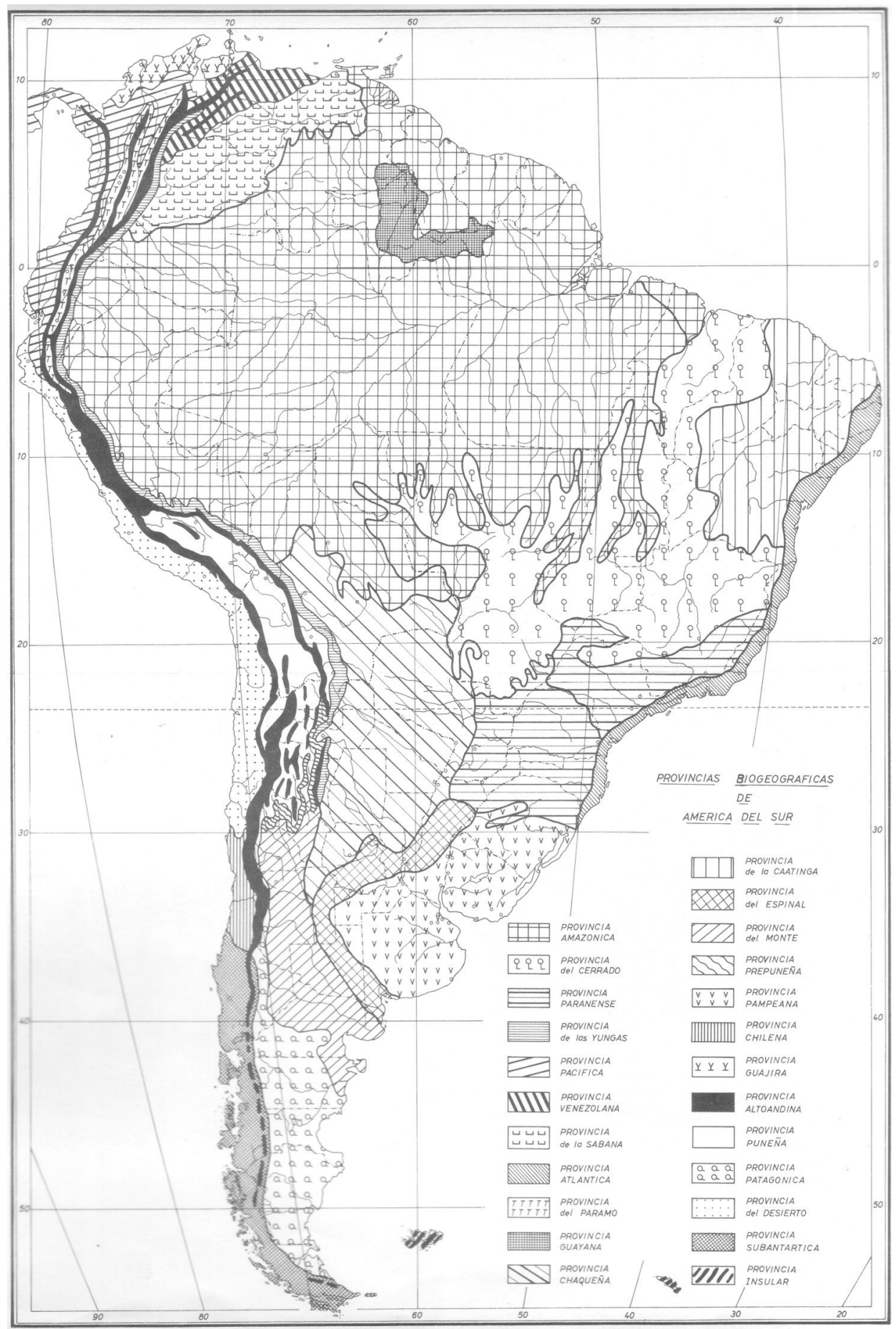

Fig. 2. Provincias Biogeográficas de AMérica del Sur tomado de Cabrera 1980 
La Pampa y el Noroeste de Buenos Aires) y Pampeano Austral: (Sur de Buenos Aires, desde las sierras de Olavarría, Tandil y Balcarce hasta cerca de Bahía Blanca) (Cabrera 1980).

En cambio Soriano et al. (1992), siguiendo a Burkart (1975) divide a la región de pastizales en dos sub-regiones (Fig. 3). La primera bajo el nombre de Pampa la cual se extiende en la provincia de Buenos Aires y en partes de la provincia Entre Ríos, Santa Fé, Córdoba, La Pampa y San Luis (Soriano 1979, León y Anderson 1983 en Soriano et al. 1992) y la segunda la denomina Campos que se encuentra en Uruguay y en la parte meridional de Río Grande do Sul (Brasil).

Los límites geográficos de la región de pastizales están determinados cuando se produce el contacto con el bosque, o con concentraciones de árboles en la región de pastizales, como galerías de árboles a lo largo de los arroyos en Uruguay o formando sectores aislados en los pastizales del sur de Brasil. La zona de galerías más importantes se encuentra en los ríos Paraná, Uruguay y en el borde del río de La Plata. Además hay una vegetación arbustiva en las áreas rocosas en las sierras de La Ventana y Tandil y la zona dorsal de las encadenadas. El bosque xerófilo esta presente en una faja en el Este de la provincia de Buenos Aires, sobre paleodunas o cordones de conchillas (Soriano et al. 1992).

En el Oeste, en las provincias de San Luis y La Pampa es difícil la definición de un límite preciso porque es una zona que ha sido totalmente alterada por las actividades agrícolas. Sin embargo es posible detectar que los pastizales naturales penetran la región de bosques xerófilos en el Oeste, como ocurre en el sector donde se unen las provincias de San Luis, Córdoba y La Pampa. El cambio en el límite es distinguible con la provincia de Entre Ríos, en donde un área llana de pastizales al sur del paralelo $32^{\circ}$ que contrasta con los bosques que se extienden al norte sobre las ondulaciones, localmente conocidas como cuchillas (Soriano et al. 1992).

Para Soriano et al. (1992), el límite norte de los Campos de la provincia de Río Grande do Sul, se extiende hasta la latitud de $28^{\circ} \mathrm{S}$ y en algunas áreas con una altitud de 700 m.s.n.m. Este límite atraviesa el río Uruguay y sigue por la provincia de Misiones en Argentina, que es el borde propuesto para los Campos por Martínez Crovetto (1963 en Soriano et al. 1992).

Los territorios zoogeográficos están usualmente asociados a los fitogeográficos, y por lo tanto es necesario, hasta donde sea posible, examinarlos como unidades ecológicas para encontrar los límites de las distribuciones de flora y de fauna (Soriano et al. 1992). En términos generales se ha seguido la clasificación zoogeográfica propuesta por Ringuelet (1955) y Ringuelet y Aramburu (1957). Estos autores proponen que desde la zoogeografía, la región pampeana es una zona transicional entre la sub-región del Guayano-Brasilera del Dominio Subtropical y la sub-región Austral. Ringuelet (1955) considera la zona ribereña del Paraná-La Plata como una intrusión subtropical, con fauna que proviene del norte. En lo que refiere al resto de la provincia biogeográfica considera que los elementos faunísticos son principalmente brasileños, si bien se advierte una fuerte influencia patagónica especialmente en el límite sur (Cabrera 1980). 


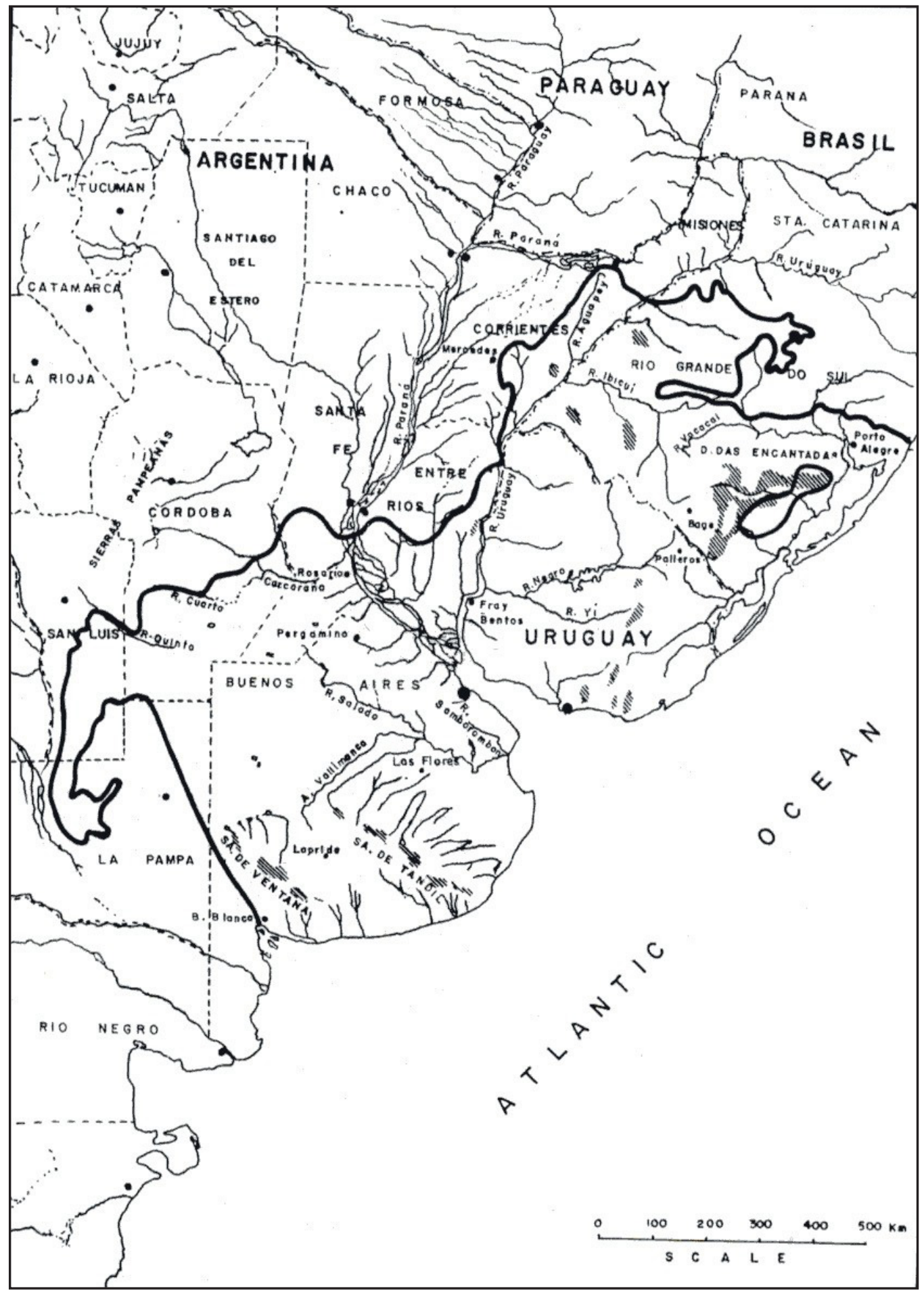

Fig. 3. Pastizales del Río de La Plata tomado de Soriano et al. 1992. 
En la región pampeana los mamíferos masa conspicuos son la vizcacha (Lagostomus maximus) y algunos marsupiales, como la comadreja (Didelphys azarae). Hay pocos carnívoros: zorrinos (Conepatus), zorro (Dusicyon), hurón (Galictis) y el gato montés (Felis geoffroyi). Hay numerosos roedores, como la mara (Dolochotis australis), tucotucos (Ctenomys), cuises (Cavia, Microcavia), el carpincho (Hydrochoerus), etc. (Cabrera 1980). Se encuentran representadas aves arborícolas y los vertebrados pisciformes, según Ringuelet, son en su mayoría subtropicales que llegan por las cuencas del Paraná y el Plata. Se destacan la lamprea (Geotria australis), la anguila criolla (Synbranchus marmoratus), el pejerrey (Basylichtys), etc. (Cabrera 1980).

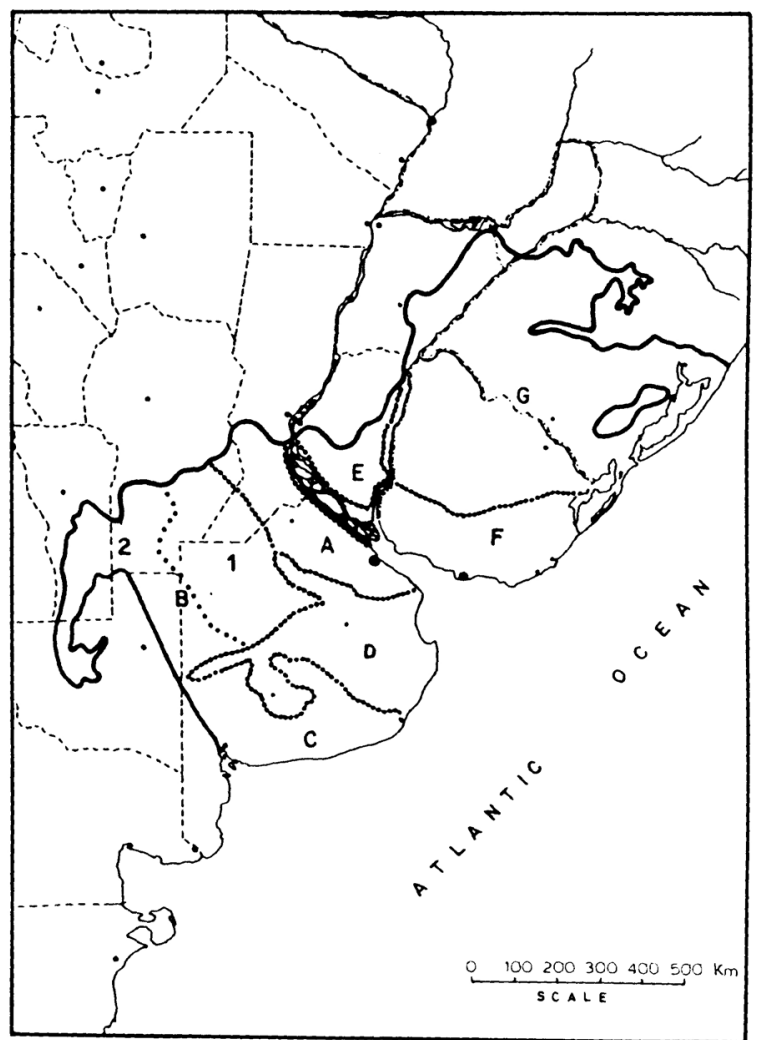

Fig. 4. Subdivisiones de la región de Pastizales del Río de La Plata. A. Pampa Ondulada. B. Pampa Interior, 1. Pampa llana o plana y 2. Pampa Oeste. C. Pampa Sur. D. Pampa inundable. E. Pampa mesopotámica. F. Campos Sur y G. Campos Norte. Tomado de Soriano et al. 1992.

Retornando a la fitogeografía y teniendo en cuenta las consideraciones previas se puede observar a partir del trabajo de Cabrera (1980) y Soriano et al. (1992) que lo que arqueológicamente se denomina región pampeana está integrada por cuatro ambientes diferentes: pastizales Pampeanos, los montes xerófilos de las pcias. del Monte y del Espinal y la cuña de bosque subtropical en galería (Fig. 5) 


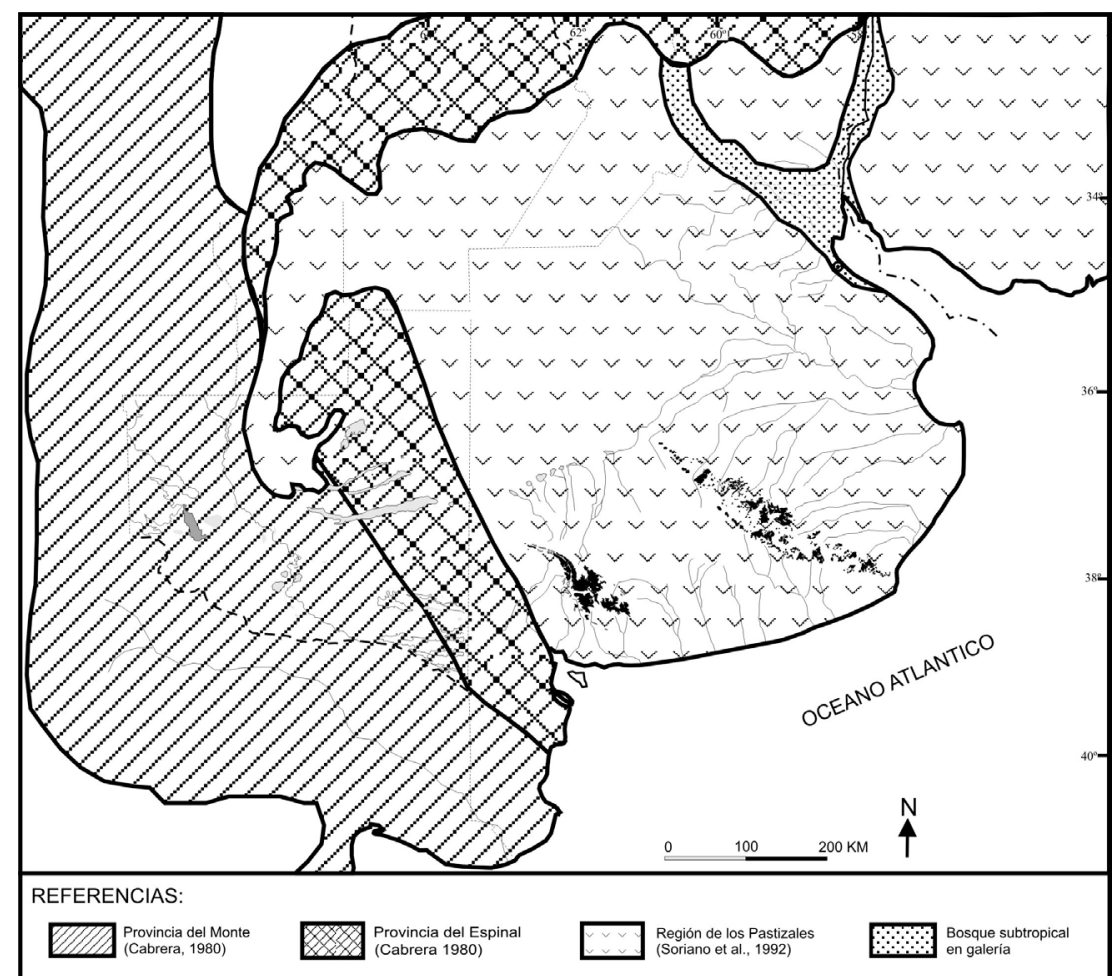

Fig.5 La región pampeana y sus provincias fitogeograficas. (Tomado y modificado de Cabrera 1980 y Soriano et al., 1992).

\section{Los patrones adaptativos básicos de la región pampeana}

Dentro de la región pampeana se han detectado varios patrones adaptativos que se comenzaron a diferenciar probablemente a partir del Holoceno Temprano. Estos patrones, que dejaron su impronta en el registro arqueológico, se definieron en base a las estrategias de subsistencia, la tecnología y la manera de ocupación del espacio. Los grupos que habitaron la región pampeana fueron básicamente cazadores-recolectores desde el inicio de la ocupación humana (ca. 12.000 años AP) hasta el siglo XV. Sin embargo, en algunas áreas la pesca tuvo un papel significativo en la subsistencia. Además, en la llanura aluvial del río Paraná Inferior-Plata hubo una horticultura a pequeña escala hacia finales del Holoceno. Dentro de este patrón adaptativo básico cazador-recolector, se observan algunas variaciones significativas que son más evidentes a partir del Holoceno tardío. Para los momentos previos la información de las diferentes áreas es muy disímil y más escasa (véanse Politis y Madrid 2001, Martínez y Gutiérrez 2004). De hecho, para la mayoría de las áreas (e.g.; Depresión del Salado, Norte, Caldenar, Ventania, Sur, etc.) los sitios datados se asignan casi exclusivamente al Holoceno tardío. Esta ausencia de registro temprano parece estar más relacionada con problemas de visibilidad arqueológica, de procesos geomorfológicos 
y de formación de sitios en general que con la falta de ocupación humana de estas áreas durante el lapso Pleistoceno final-Holoceno medio.

En su síntesis sobre las tendencias de la explotación faunística en la región pampeana Martínez y Gutiérrez (2004:88-89) plantearon tres modos de subsistencia diacrónicos. Uno para el lapso Pleistoceno tardío-Holoceno temprano que se caracteriza por una economía regional generalizada, otro para el Holoceno medio que corresponde a una economía regional especializada y una tercera para el Holoceno tardío definida por economías areales de diversificación e intensificación. Asumiendo estas estrategias de subsistencias diversificadas en el Holoceno tardío, se pueden definir por lo menos tres patrones adaptativos básicos en la región (Fig 6):

A) Cazadores-recolectores de los pastizales pampeanos.

B) Cazadores-recolectores de los bosques xerófilos (del espinal y del monte).

C) Cazadores-recolectores-pescadores fluviales y lagunares de ambientes subtropicales y templados cálidos.

A) Cazadores-recolectores de los pastizales pampeanos.

La definición de este patrón adaptativo se basa en el abundante registro de sitios en las áreas Interserrana y Tandilia (véanse entre muchos otros Salemme 1987, Crivelli et al. 1997, Politis 1988, 2000, Politis y Madrid 2001, Mazzanti y Quintana 2001, Bonomo 2004, Martínez y Gutiérrez 2004). En las áreas de Ventania, Sur y Oeste la información sobre las estrategias de subsistencia y uso del espacio es mucho más escasa (e.g., Oliva et al. 1991a y b). En algunos sectores en particular casi no hay datos disponibles de ningún tipo, como por ejemplo gran parte de la llanura de las provincias de Santa Fé, San Luis y el sureste de la provincia de Córdoba.

Aunque la asociación faunística en la mayoría de los sitios del Holoceno tardío, indica la explotación del guanaco (Lama guanicoe) como especie principal y del venado de las pampas (Ozotoceros bezoarticus), ñandú (Rhea americana) y de varias especies de armadillos y roedores, como especies de importancia secundaria (e.g., Politis y Salemme 1990, Oliva et al. 1991b, Crivelli Montero et al. 1997, Mazzanti y Quintana 2001, véase resumen y discusión en Martínez y Gutiérrez 2004), hay algunas diferencias interesantes de mencionar. En las cuevas de Tandilia, durante el Holoceno medio y tardío, el guanaco y el venado habrían tenido una importancia similar en la dieta, mientras que para la última parte del Holoceno tardío el lagarto overo (Tupinambis cf. merianae), el coypo (Myocastor coypus) y algunos roedores cávidos fueron importantes para la subsistencia (Quintana y Mazzanti 2001). En estos sitios se ha registrado también el consumo ocasional de los bagres Rhamdia cf. sapo y Corydoras cf. paleatus

Deben diferenciarse los sitios arqueológicos que se encuentran en el área de Tandilia y Ventania con los del área Interserrana. En Tandilia predominan las ocupaciones en cuevas pequeñas con redundancia de ocupación desde el Pleistoceno tardío. Para el área Interserrana la mayoría de los sitios detectados han sido caracterizados como de actividades 
múltiples y se encuentran a orillas de lagunas y arroyos. Recientemente Bonomo (2004) ha propuesto un modelo de ocupación humana de la costa atlántica del área Interserrana en donde también se destaca el papel central del guanaco en la dieta, incluso en sitios que están a pocos kms del litoral, tales como Nutria Mansa 1 (Bonomo 2004) o Quequén Salado 1 (Madrid et al. 2002).

Es interesante destacar que a pesar que se ha planteado, en base a análisis isotópicos de Delta C13, que durante el Holoceno temprano/medio los cazadores de la llanura pampeana habrían consumido ocasionalmente o estacionalmente productos marinos (Barrientos 1999), para el Holoceno tardío no hay ninguna evidencia clara de esto. Los únicos datos de explotación de mamíferos marinos provienen del sitio La Olla, datado en ca. 7800 a 6500 años AP (Bayón y Politis 1996 y 1998).

La mayoría de los autores han planteado el consumo de especies vegetales, pero las evidencias son en general indirectas, ya que se basan en la presencia de elementos de molienda que aparecen con frecuencia en los sitios pampeanos. En algunos de ellos, estos elementos son muy abundantes (véase Zanjón Seco, Martínez 1999 y Nutria Mansa, Bonomo 2004). Sin embargo aún no está claro qué especies vegetales se procesaban en estos artefactos. La ausencia de árboles en los pastizales pampeanos limita los potenciales frutos para los que se podrían haber usado estos artefactos. Las pocas excepciones son los bosques de tala (Celtis tala), que se desarrollan desde el litoral del Río de la Plata hasta la laguna de Mar Chiquita, y los sauces criollos (Salix humboldtiana) que crecen en los ríos $\mathrm{y}$ arroyos que nacen en el sistema de Ventania. Estos bosques ocupan una superficie ínfima dentro de los pastizales pampeanos y en general no tienen frutos comestibles. Los estudios sobre residuos orgánicos e inorgánicos en artefactos de molienda, que están aún en etapas iniciales, son una de las vías de abordaje de este problema (véase Tapia y Charlín 2004, Zucol y Bonomo 2005, Osterrieth y Tassara 2005).

\section{B) Cazadores-recolectores del monte xerófilo}

Este patrón adaptativo está mucho menos representado, sobre todo, por la escasez de investigaciones llevadas a cabo en áreas con monte xerófilo. La mayor parte de la información proviene de tres sectores: Casa de Piedra (Gradín 1984), la localidad de Tapera Moreira (Berón 2004) y el curso inferior del río Colorado (Martínez 2004). Como en el caso anterior, el guanaco fue la especie mas explotada y ocupó un rol central dentro de la dieta de las poblaciones indígenas. El venado de las pampas, los armadillos y las aves fueron recursos secundarios. En comparación con los cazadores-recolectores de los pastizales, la explotación faunística incluye en este caso una menor diversidad de especies (Martínez y Gutiérrez 2004).

A juzgar por la abundancia de morteros y en base a datos etnohistóricos, es probable que los grupos humanos que ocuparon el área hayan consumido los frutos de los bosques del espinal y del monte. Algunas especies, tales como el chañar (Geoffre decorticans) y el algarrobo (Prosopis sp), tienen frutos comestibles y su consumo está ampliamente documentado en las fuentes escritas. De todas maneras, en el registro arqueológico aún no 
hay evidencias conclusivas del consumo de frutos del bosque. Sin embargo, la abundancia de elementos de molienda en la mayoría de los sitios que se encuentran en el monte xerófilo sugiere un importante procesamiento de vegetales en este sector. Además, la información isotópica recientemente obtenida sobre restos humanos del Holoceno tardío en el extremo suroriental del bosque del espinal sugiere una dieta básicamente continental compuesta por la incorporación de herbívoros consumidores de plantas $\mathrm{C} 3 \mathrm{y} / \mathrm{o}$ el consumo directo de estos vegetales (Martínez 2004).

Es interesante destacar que en las localidades de Casa de Piedra y Tapera Moreira se observa una redundancia ocupacional en los sitios. Esto estaría en parte ocasionado por la escasez de agua en estas áreas, lo que fue determinante para la instalación de los campamentos. Como discutió Berón (2004), el hecho de que el agua haya sido un recurso crítico durante todo el Holoceno fue central en las estrategias de uso del espacio y en los patrones de movilidad.

En la zona del curso inferior del río Colorado se han detectado estrategias de subsistencia con algunas particularidades. Este sector se encuentra dentro del Distrito del Caldén de la provincia del Espinal y es una zona transicional entre Pampa y Patagonia. Como en el resto del bosque xerófilo, hay abundantes evidencias que indican que durante el Holoceno tardío el guanaco tuvo un lugar central en la dieta y en segundo orden se encontraban el venado de las pampas, dasipódidos y ñandú. El consumo de vegetales de la provincia del Espinal también se incluyó dentro de la subsistencia, sobre todo a partir del 1000 AP aunque es difícil estimar aún en que porcentaje (Martínez 2004). Lo novedoso dentro de este patrón adaptativo es que en este sector se ha detectado la explotación de peces de agua dulce y de mar. Se destaca el registro del sitio El Tigre en el cual las percas habrían sido consumidas con intensidad (Martinez et al 2005). Los recursos marinos parecen haber sido explotados en mucha menor medida y al igual que en el área Interserrana, habrían contribuido a la dieta humana en muy bajo porcentaje.

C) Cazadores-recolectores-pescadores fluviales y lagunares.

Este patrón adaptativo se manifiesta de tres maneras dentro de la región pampeana que se encuentra en tres sectores del Noreste de la región pampeana (Politis y León 2005):

Cazadores-recolectores-pescadores del litoral fluvial y delta del Paraná. Este patrón se ha identificado en el Paraná Inferior, incluyendo el Delta, y va desde el río Carcarañá hasta el inicio del actual río de La Plata (Tigre).

Cazadores-recolectores-pescadores fluviales y de estuario. Este patrón ocupa la orilla de lo que hoy es el río de La Plata, desde Tigre hasta Punta Piedras.

Cazadores-recolectores-pescadores lagunares. Este patrón se ha identificado en la actual llanura aluvial del estuario del río de La Plata, curso inferior del río Salado y las lagunas adyacentes. 


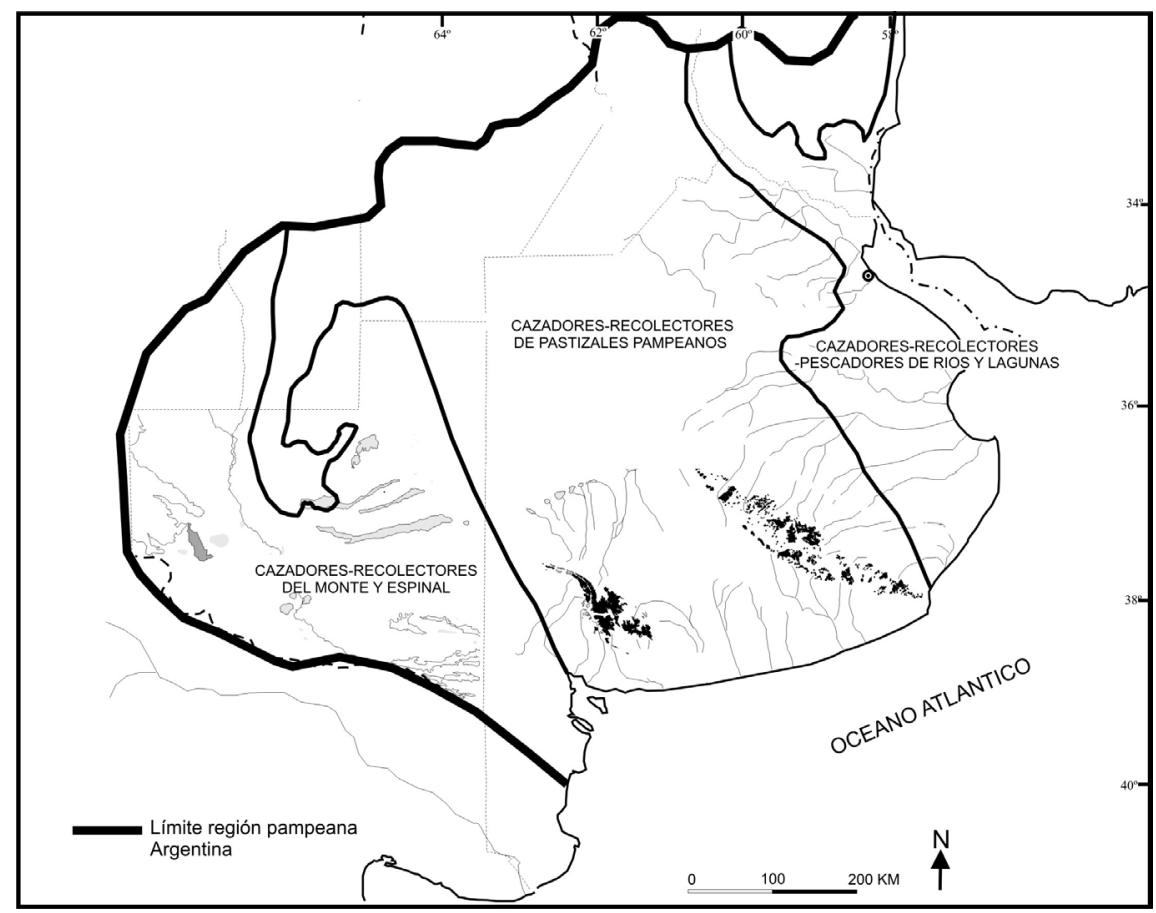

Fig 6. Patrones adaptativos de la región pampeana.

\section{-- Cazadores-recolectores-pescadores del litoral fluvial y delta}

Este patrón adaptativo se caracteriza por la explotación de los ambientes lagunares de la llanura aluvial del río Paraná y del Delta. Las estrategias de subsistencia se basaron en la explotación del coipo, el cuis (Cavia aperea) y los peces de las familias, Doradiade y Pimelodidae, como recursos principales. También se explotaron las dos especies de venado (de las pampas y de los pantanos) y una variedad de fauna menor, incluyendo moluscos de agua dulce del género Diplodon. (Loponte y Acosta 2003, Martínez y Gutiérrez 2004). Etnográficamente está documentada la utilización de recursos del bosque en galería, aunque arqueológicamente el registro es muy escaso. Este es un ambiente de una gran oferta de recursos vegetales potencialmente comestibles, entre los que se destacan las palmas. Uno de los pocos datos arqueológicos que apoya el consumo de frutos de palma proviene del sitio Las Vizcacheras en donde se recuperaron restos carbonizados de endocarpos de pindó o palmera datilera (Syagrus romanzoffiana) (Loponte et al. 2004 a y b).

Para épocas más tardías se ha planteado la incorporación en la dieta de productos cultivados, por lo menos para algunos de los grupos que habitaron este sector. Esto está claramente evidenciado en los documentos escritos, pero los datos arqueológicos son también muy excepcionales. Recientemente, Loponte y Acosta (2003) han planteado, en base a análisis isotópicos, que uno de los individuos del sitio Arroyo Malo pudo haber consumido maíz. 
Para este tipo de patrón adaptativo se ha propuesto una baja movilidad residencial, la que estaría favorecida por la abundancia de recursos fluviales y deltáicos. En general se trata de sitios en zonas altas, no inundables, con elevado porcentaje de restos materiales entre los que se destacan la alfarería y las valvas de moluscos dulceacuícolas. Es también frecuente el uso de estos lugares como sitios de entierros humanos. Es probable que se trate de lugares reocupados o con lapsos de ocupación relativamente prolongados.

\section{--Cazadores-recolectores-pescadores fluviales y de estuario}

Los sitios en los cuales se ha detectado este patrón adaptativo están en las orillas del río de La Plata y muestran altas densidades de materiales, lo que sugiere cierta estabilidad en las ocupaciones (Brunazzo 1997, 1999, Paleo y Pérez Meroni 2001 y 2004). La estrategia de subsistencia se caracteriza por el consumo del venado de las pampas y en diferentes porcentajes, de cuis, coipo, ciervo de los pantanos y peces de agua dulce de la familia Pimelodidaes y Doradidaes. En la mayoría de los sitios de este sector aparece corvina negra (Pogonias cromis), un pez de agua salada típico de zonas de estuarios. Las evidencias de consumo de esta especie constituyen una particularidad dentro de los cazadores-recolectores-pescadores fluviales y lagunares. En lo que respecta a la presencia de recursos vegetales, en el sitio La Higuera (Brunazo 1997) se recuperó carbón vegetal de una estructura lenticular de fogón. Las especies vegetales determinadas fueron molle, Schinus sp) y chañar (Geoffrea sp), ambas presentes en los bosques de tala de este sector.

La presencia de corvina negra en sitios sobre la orilla del río de La Plata merece una breve discusión (Politis y León 2005). En la actualidad, el estuario del río de La Plata se extiende desde la línea que une Punta Piedras (Argentina) y la desembocadura del río Santa Lucía (Uruguay), hasta unos $150 \mathrm{~km}$ hacia el mar abierto, conformando el límite exterior. Los estuarios, en general, se caracterizan por poseer una interfase fluvio marina. En el estuario del río de La Plata, en particular, esta interfase se caracteriza por que el agua dulce aportada por el río de La Plata al llegar a la línea Pta. Piedras-río Sta. Lucía se desplaza por encima del agua marina la cual se desliza en dirección contraria. Para el Holoceno tardío dicho estuario se encontraba en una posición completamente diferente. Durante el máximo de la transgresión marina holocénica (6000 A.P) el nivel del mar ascendió hasta 6,5 m (Fidalgo et al. 1973). Dicho ascenso fue acompañado por la zona estuárica hasta las actuales ciudades de Santa Fe y Paraná (Cavalloto 1995). En el Holoceno final (ca. 3500 AP) el frente salino de fondo llegaba hasta las actuales Islas de las Lechiguanas y en el 2000 A. P. hasta la actual ciudad de Buenos Aires. O sea que en el momento en que los sitios fueron ocupados, el río de La Plata funcionaba como un estuario que se estaba desplazando hacia su posición actual. De esta manera probablemente el sitio La Norma (aun sin fechar) estaría en la orilla del estuario (lo que explica la presencia de corvina negra), mientras que cuando se ocupó la Higuera (datado en $500 \mathrm{AP}$ ) ya no estaba el estuario sino el río (lo que explica la ausencia de corvina negra). Los sitios de San Clemente 2, 3, y 6 con dataciones entre 800 y 1500 años A.P. y Las Marías (Paleo et al. 2002; Paleo y Pérez Meroni 2001) estuvieron ocupados mientras ese sector era zona estuárica, y tienen corvina negra, mientras que el sitio más tardío (San Clemente 4) no presenta esta especie. 


\section{-- Cazadores-recolectores-pescadores lagunares}

Este patrón adaptativo se basa en información arqueológica obtenida en la Depresión del Salado. Este área se ha transformado en un punto clave en el debate actual porque fue planteada como una frontera entre dos tipos adaptativos diferentes (véanse Madrazo 1979, Orquera 1987, Politis 1985, Berón y Politis 1997, González de Bonaveri 2005). En base a los recientes datos aportados por González de Bonaveri (2005) y por otros autores (e.g. Aldazabal 1991, 1992, Aldazabal y Cáceres 1999, De Feo et al. 1995) parece necesario diferenciar dos zonas dentro de lo que se ha denominado Depresión del Salado. Una zona baja, que incluye el sector oriental de la provincia de Buenos Aires y que se encuentra aproximadamente por debajo de la cota de los $30 \mathrm{~m} / \mathrm{s} / \mathrm{n} / \mathrm{m}$., y otra más alta que se extiende hasta las llanuras altas periféricas del Sistema Serrano de Tandilia y hacia las cotas más elevadas que limitan con la Pampa Ondulada. La zona baja oriental está mal drenada y abundan las lagunas, muchas de las cuales en épocas de inundación se conectan con el río Salado y sus afluentes. También, a diferencia de la otra zona más alta, presenta un bosque continuo en la faja costera dominado por el tala (Celtis tala), el cual constituye un recurso potencial importante (González de Bonaveri 2005). Durante el Holoceno medio (ca. 7000-6500 a 3000 años AP) y parte del Holoceno tardío, un sector de la zona baja oriental, sobre todo debajo de la cota de los $5 \mathrm{mts}$, estuvo bajo el agua y, por lo tanto, es una zona que volvió a quedar disponible para los seres humanos en los últimos milenios (ver discusión en Aldazabal et al. 2004). Los sitios estudiados por González de Bonaveri (2004) están precisamente en el sector de lagunas y lomadas de la zona baja y muestran algunas diferencias significativas con el registro de la zona más alta de la Depresión del Salado (véanse los datos aportados por los sitios La Colorada y Pessi, Aldazabal y Cáceres 1999 y Aldazabal et al. 2004). En suma, parecería que a estas diferencias ambientales entre la zona alta y la baja, le corresponde una diferencia en el registro arqueológico, cuyo significado en términos culturales es aún difícil de entender, debido, fundamentalmente, a la escasez de datos en la primera de las zonas mencionadas.

Para el Holoceno tardío, en la zona baja, los patrones adaptativos básicos se asemejan a los del litoral del Paraná-Plata, lo que indica una mayor estabilidad de los sitios con abundancia de alfarería. Las estrategias de subsistencia se basan en la explotación del coypo y de peces de la familia Pimelodidae (Rhamdia sapo). También se ha registrado el consumo de las dos especies de cérvidos presentes en la región y de aves de ambientes acuáticos (mayoritariamente del genero Fulica sp). En la zona más alta de la Depresión del Salado, los sitios sugieren ocupaciones más cortas y una subsistencia basada en el guanaco y el venado, en términos generales, similar a la de los cazadores-recolectores de los pastizales.

\section{Consideraciones finales}

En base a lo expuesto, el primer punto para examinar son los límites de la región a partir de las características ecológicas. En principio éstos no son claros y dependen de los criterios que se utilicen para su demarcación. Algunas fronteras han sido consensuadas 
más fácilmente porque están vinculadas a grandes ríos. El río Colorado al Sur y el Paraná/ Plata al Este son los límites más claros. Sin embargo, en base a Soriano et al (1992), y teniendo en cuenta la dominancia de los pastizales como una característica distintiva de la región pampeana, se deberían incluir también los pastizales del sur de la provincia de Entre Ríos, (lo que se ha llamado Pampa mesopotámica). Hacia el norte, en las llanuras santafesinas, la región pampeana gradualmente se transforma en la chaqueña. Aquí, los límites son más imprecisos y de cierta manera fluctuantes ya que la diferenciación del paisaje natural en el límite de la Pampa con el Chaco, a partir de la eliminación del bosque y la incorporación de la actividad agrícola, no puede observarse en forma nítida (Daus 1969). Nuevamente, Soriano et al (1992) identifica el límite de los pastizales al norte del río Carcarañá aproximadamente en el paralelo $32^{\circ}$. Este entonces podría ser un límite convencional, aunque como se expresó, la transición entre los pastizales y los bosques xerófilos son relativamente graduales en ese sector. En una perspectiva desde la región chaqueña también se percibe esta gradualidad del cambio entre ambas regiones. Por ejemplo, en una síntesis reciente sobre los indígenas del Chaco, Wright (2005) expresa que "Como Región ecológica, el Chaco es una vasta planicie de casi un millón de kilómetros cuadrados. La región se extiende desde las selvas tropicales de Bolivia y las sierras subandinas del noroeste argentino hasta la llanura pampeana con la que se va fundiendo gradualmente en el Norte de las provincias de Córdoba y Santa Fé” (Wright 2005:25-26).

Hacia el Oeste, el borde de la región pampeana es difuso e incluye el arco de bosques de la Provincia del Espinal y una parte de los bosques de la del Monte. Esta zona se encuentra también muy degradada por la actividad agrícola-ganadera. Estos bosques xerófilos bordean los pastizales por el sur, hasta encontrase con el río Colorado que es considerado el limite meridional de la región.

En términos arqueológicos, los bosques xerófilos del sur de San Luis, sureste de Córdoba y norte de La Pampa se incluyen dentro de la región pampeana, aunque claramente este no es un ambiente de pastizales y pertenece a otras provincias fitogeográficas. Este sector es muy poco conocido arqueológicamente y no es posible identificar aún los patrones adaptativos básicos. En principio, muestran algunas diferencias con las dos localidades del sur (Casa de Piedra y Tapera Moreira). Además, los trabajos de Aguerre (1996) indican que en el norte de la provincia de la Pampa, los patrones estilísticos y la tecnología se relacionan más con los de las Sierras Centrales que con los de la región pampeana (véase por ejemplo el caso de la cerámica de la laguna Chadilauquen).

Hacia el Sur, en términos arqueológicos Outes (1926) mencionó al valle del río Colorado como el límite meridional de la región pampeana, aunque éste no es un ambiente de pastizales, sino del bosque del espinal (Fig. 5). Recientemente las investigaciones de Martínez y su equipo (Martínez 2004, Martínez et al. 2005 ) señalan un tipo de adaptación a bosques xerófilos, pero con un complemento importante en la explotación de peces de agua dulce.

En suma, lo que llamamos región pampeana en el ámbito de la arqueología de América del Sur es un mosaico ambiental y cultural. Aunque las llanuras de pastizales 
sin árboles predominan en la región, otros ecosistemas se encuentran bien representados, tales como los bosques de floresta tropical en galería que penetran hacia el sur como una cuña en los ríos Paraná y Uruguay y los bosques xerófilos que forman un arco rodeando los pastizales. Desde el punto de vista cultural hay una diversidad de patrones adaptativos dentro de los cuales ha predominado el de cazadores de guanaco, con alta movilidad y una tecnología lítica unifacial de cuarcita y ftanita. Sin embargo por lo menos para el Holoceno tardío hay otros patrones adaptativos básicos que incluyen a los cazadores-recolectorespescadores fluviales y lagunares, tanto en el Paraná-Plata como en el río Colorado. Además, en sectores del delta del río Paraná y en la llanura aluvial del río Uruguay también se practicó una horticultura a pequeña escala. Estas diferentes adaptaciones parecen provenir de trayectorias históricas distintas (o como clásicamente se denominaba, de "tradiciones diferentes").

Parece claro que las sociedades indígenas de la segunda mitad del Holoceno tardío que habitaron la depresión del Salado, el litoral del Paraná-Plata y el delta del Paraná tenían una forma de vida similar a la de los ribereños de las Tierras Bajas Subtropicales. Los indígenas de la Tierras Bajas Subtropicales, un ambiente dominado por una floresta relativamente densa en donde hay algunas áreas de sabanas tropicales, presentan esrategias de subsistencia comunes. Básicamente, esta macro-región ha sido habitada por sociedades que combinaban una economía mixta basada en la caza, la pesca, la recolección (tantos de plantas como de insectos) y la horticultura de roza y quema, básicamente de mandioca (dulce y amarga) (e.g., Lowie 1949, Steward 1949, Meggers 1971). Otros cultígenos importantes u extendidos eran el maíz (Zea mays) y la batata (Ipomea batata). La gran mayoría de los grupos que habitan el área practicaban todas estas estrategias de subsistencia pero las combinaron de diferente manera. Al momento de la llegada de los europeos, existían pocos grupos foragers "puros" y por otro lado, la inmensa mayoría de los horticultores practicaban la pesca, la caza y la recolección como elementos complementarios importantes en la dieta. Esta flexibilidad adaptativa permitió que muchos grupos horticultores ribereños, especialmente los de tradición Tupí-Guaraní (i.e. Guajá, Sirionó, etc.) se transformen en foragers altamente móviles como una estrategia de defensa ante los conquistadores (véase discusión en Politis en prensa).

Los patrones adaptativos básicos registrados en la zona baja de la Depresión del Salado, y del litoral Paraná Inferior-Plata se diferencian de los cazadores-recolectores de pastizales pampeano-patagónicos. La información de los sitios de la parte baja de la Depresión del Salado indica en primer lugar una economía basada en la explotación intensiva de pequeños mamíferos vinculados con ambientes acuáticos (como el coipo) y en segundo lugar de animales medianos (como el venado de las pampas), de aves y un fuerte componente en la pesca. También se ha detectado el uso de los productos del bosque de tala, tanto la madera para leña como posiblemente algunos frutos. Esto es claramente diferente a la subsistencia inferida para los cazadores pampeano-patagónicos que basaban su economía en el guanaco y que, salvo algunas excepciones (como las que ha comenzado a identificar Martínez para el río Colorado), no pescaban ni cazaban aves ni mamíferos acuáticos regularmente. De la misma manera, la movilidad de estas poblaciones parece 
haber sido menor que la de los indígenas que habitaban al sur, y la alta densidad de restos (especialmente alfarería) sugiere estadías más prolongadas o reocupaciones más frecuentes de los sitios. La tecnología cerámica y la variedad de motivos decorativos, muestran mayores semejanzas con el litoral que con Pampa-Patagonia.

La vinculación de los cazadores-recolectores-pescadores del sector bonaerense del Paraná Inferior-Plata con las tradiciones culturales de la Mesopotamia Argentina y de las Tierras Bajas Tropicales, había sido ya planteada por varios autores desde hace décadas (e.g., Howard 1948, Aparicio 1949, Serrano 1955, Lafón 1971). Estos investigadores incluyeron la información de la faja noreste y del Delta del Paraná en las revisiones que hicieron de la arqueología del Noreste Argentino. Lo novedoso es que con los resultados obtenidos por González de Bonaveri (2005), Brunazzo (1997, 1999) y Paleo y Pérez Meroni (2004), estas estrategias de susbsistencia se extienden más hacia el Sur incluyendo el litoral del río de la Plata y la zona baja de la Depresión del Salado, la que podría considerarse ahora la frontera de la expansión meridional de los patrones adaptativos de las Tierras Bajas Tropicales.

En suma, parece claro que lo que llamamos región pampeana dentro de la arqueología de América del Sur es una unidad espacial que no corresponde a una unidad ecológica ni cultural. Aunque predominan las llanuras abiertas de pastizales de clima templado, dentro de la región pampeana se observan por lo menos otros tres ambientes distintos: una cuña de bosque subtropical en galería y los bosques xerófilos de las provincias del espinal y del monte. En términos culturales, se han identificado, por lo menos para el Holoceno tardío, tres patrones adaptativas diferentes, los que posiblemente sean el resultado de trayectorias históricas distintas. Teniendo esto en cuenta, se debe concluir que el uso de la región pampeana, tal cual está definida actualmente, como unidas análisis se basa en tradiciones de investigación y en cierto consenso contemporáneo más que en características ecológicas o arqueológicas distintivas.

Agradecimientos: A Luciano Prates y a Alejandra Matarrese por los comentarios y sugerencias, a Cristian Kaufmann y a Diego Gobbo por la realización de los mapas. Este trabajo es resultado de las investigaciones llevadas a cabo desde el programa INCUAPA (Investigaciones Arqueológicas y Paleontológicas del Cuaternario Pampeano), subsidiado por la ANPCYT (PYCT nro. 04-12776) por el CONICET (PIP nro. 5424 ) y subsidios de la Secretaría de Ciencia y Técnica de la Unuiversidad Nacional del Centro de la Pcia. de Buenos Aires,

\section{Bibliografía}

Aguerre, A. 1996. Arqueología en la Laguna Chadilauquen. E(e)studios P(p)ampeaños. Edición especial 1. I. A. R Instituto de Antropología Rural. Universidad Nacional de La Pampa. La Pampa. pp 19-43.

Aldazabal. 1991. Arqueología de la Costa Central de la Provincia de Buenos Aires. Comparaciones con áreas vecinas. Boletín del Centro 3:96-104. 
Aldazabal. 1992. Resultados de una prospección arqueológica realizada en la costa central de la Provincia de Buenos Aires. Palimpsesto 2:5-20.

Aldazabal, V. y L. Cáceres. 1999. Primeras observaciones arqueológicas en el sitio La Colorada, Partido de Rauch, Provincia de Buenos Aires. Actas del XII Congreso Nacional de Arqueología Argentina, III, pp.95-100. La Plata.

Aldazabal, V., N Weiler y E. Eugenio. 2004. Una perspectiva geoarqueológica para comprender la ocupación humana en la costa central de la provincia de Buenos Aires. Intersecciones en Antropología 5:19-38.

Ameghino, F. 1880. La Antigüedad del Hombre en el Plata. Obras Completas y Correspondencia Científica de Florentino Ameghino, Vol. III (1915). La Plata.

Aparicio, F. de. 1949. The Archaeology of the Paraná River. En Steward, J. (ed.); Handbook of South American Indians 3:57-68. Washington, Smithsonian Institution.

Aparicio, F. de y H. Difrieri. 1958. La Argentina. Suma de Geografía, Tomo I. Ediciones Peuser. Buenos Aires.

Austral, A. 1971. El yacimiento arqueológico Vallejo en el NO de La Pampa. Relaciones de la Sociedad Argentina de Antropología. N.S. V 2: 49-70. Buenos Aires.

Barrientos, G. 1999. Composición isotópica $\left(\ddot{\mathrm{A}}^{13} \mathrm{C}\right)$ de muestras de restos óseos humanos del sitio Arroyo Seco 2 (Provincia de Buenos Aires): Inferencias Paleodietarias. Relaciones de la Sociedad Argentina de Antropología XXIV: 81-94.

Bayón, C. y G. Politis. 1996. Estado actual de las investigaciones en el sitio Monte Hermoso 1. Arqueología 6:83-115. Buenos Aires

Bayón, C. y G. Politis. 1998. Pisadas humanas prehistóricas en la costa pampeana. Ciencia Hoy 8 (48):12-20

Berón, M. 2004. Dinámica poblacional y estrategias de subsistencia de poblaciones prehispánicas de la cuenca Atuel-Salado-Chadileuvú-Curacó, Provincia de la Pampa. Tesis Doctoral Inédita. Facultad de Filosofía y Letras, Buenos Aires.

Berón, M. y G. Politis. 1997. Arqueología Pampeana en la década de los'90. Estado de las investigaciones y perspectivas. En Arqueología de la Región Pampeana en la Década de los '90.

M. Berón y G. Politis (eds.), pp. 7-32. Museo de San Rafael-INCUAPA, San Rafael, Mendoza.

Bonomo, M. 2004. Ocupaciones humanas en el litoral marítimo pampeano: un enfoque arqueológico. Tesis Doctoral inédita, Facultad de Ciencias Naturales y Museo, Universidad Nacional de la Plata.

Brunazzo, G. 1997. Ocupación prehispánica en el litoral platense meridional: el sitio La Higuera (Partido de Berisso, Provincia de Buenos Aires). Jornada de Comunicaciones Científicas: 100. La Plata, Facultad de Ciencias Naturales y Museo, UNLP.

Brunazzo, G.. 1999. Investigaciones Arqueológicas en el sitio La Norma (Partido de Berisso, Provincia de Buenos Aires, Argentina). En Diez Marín, C. (comp.) Actas del XII Congreso Nacional de Arqueología Argentina III:101-106. La Plata.

Cabrera, A. 1980. Biogeografía de América Latina. Serie de Biología. Monografía Nro. 13. Secretaría General de la Organización de los Estados Americanos. Programa Regional de Desarrollo Científico y Tecnológico. Washington, D.C. 122 pp.

Cavallotto, J. L. 1995. Evolución geomorfológica de llanura costera ubicada en el margen sur del Río de La Plata. Tesis Doctoral inédita, Facultad de Ciencias Naturales y Museo, Universidad Nacional de La Plata. 2 Vol.

Crivelli Montero, E., E. Eugenio., U. Pardiñas y M. Silveira. 1997. Archeological investigation in the plains of the Province de Buenos Aires, Llanura Interserrana Bonaerense. Quaternary of South America and Antarctic Peninsula 10 (1994): 167-207. 
Daus, F. A. 1968. Fisonomía Regional de la Republica Argentina. Editorial Nova, Buenos Aires.

Daus, F. A. 1969. Fundamentos para una división regional de la Argentina. Instituto de Geografía “Romualdo Ardissone”. Serie A: 28. Universidad de Buenos Aires. Facultad de Filosofía y Letras.

De Feo, C., G. Balbarrey, C. Dellanegra y V. Ithurriague. 1995. Aportes a la arqueología del litoral norbonaerense: el sitio Aspiroz. Arqueología en el Uruguay. VIII Congreso Nacional de Arqueología Uruguaya. M. Consens, J .M. López Mazz y M. Curbelo (eds.), pp 413-422, Uruguay.

Delachaux, E. 1908. Las regiones físicas de la República Argentina. Revista del Museo de La Plata vol 15 (S.S., 2): 102-131.

Fernández, J. 1982. Historia de la Arqueología Argentina. Anales de Arqueología y Etnología: 320 pp. Mendoza.

Franguelli, J. 1940. Rasgos Principales de Fitogeografía Argentina. Publicaciones Didácticas y de Divulgación Cientifica del Museo de la Plata 2: 51-85.

Fidalgo, F., Colado, U.R. y F.O. De Francesco. 1973. Sobre ingresiones marinas cuaternarias en los partidos de Castelli, Chascomus y Magdalena (pcia. de Buenos Aires). Quinto Congreso Geológico Argentino 3:227-240. Buenos Aires.

Gradin, C. J. 1984. Investigaciones arqueológicas en Casa de Piedra. Editor: Ministerio de Educación y Cultura. Dirección General de Cultura. Santa Rosa. 149 pp.

González, A. R. y J. A. Pérez. 1966. El Área Andina Meridional. Actas y Memorias del XXXVI Congreso Internacional de Americanistas 1:241-265. Sevilla.

González de Bonaveri, M. I. 2005. Arqueología de alfareros, cazadores y pescadores pampeanos. Sociedad Argentina de Antropología, Buenos Aires.

Howard, G. 1948. Northeast Argentina. En Lowland Argentine Archeology. pp. 9-24. Yale University Press, London.

Lafón, C.R. 1971. Introducción a la arqueología del Nordeste Argentino. Relaciones de la Sociedad Argentina de Antropología V(2) (N.S.):119-152.

Lehmann-Nitsche, R. 1910. Catálogo de la Sección Antropológica del Museo de la Plata. Coni, Buenos Aires.

Madrazo, G.. 1973. Síntesis de la Arqueología Pampeana. Etnía 17: 13-25.

Madrazo, G.. 1979. Los cazadores a la larga distancia de la Región Pampeana. Prehistoria Bonaerense: 11-67. Olavarría.

Madrid, P., G. Politis, R. March y M. Bonomo. 2002. Arqueología microrregional en el sudeste de la región pampeana argentina: el curso del río Quequén Salado. Relaciones de la Sociedad Argentina de Antropología XXVII: 327-355.

Martínez, G. 1999. Tecnología, subsistencia y asentamiento en el curso medio del río Quequén Grande: un enfoque arqueológico. Tesis Doctoral inédita. Facultad de Ciencias Naturales y Museo, Universidad Nacional de La Plata.

Martínez, G.. 2004. Resultados preliminares de la Investigación Arqueológicas realizadas en el curso inferior del río Colorado (Pdos. De Villarino y Patagones, Pcia. de Buenos Aires). En Aproximaciones Contemporáneas a la Arqueología Pampeana. Perspectivas teóricas, metodológicas, analíticas y casos de estudio. G. Martínez, M. Gutiérrez, R. Curtoni, M. Berón y P. Madrid. (eds.), pp. 275-292 Publicación de la Facultad de Ciencias Sociales. UNCPBA. Olavarría.

Martínez, G. y M. Gutiérrez. 2004. Tendencias en la explotación humana de la fauna durante el Pleistoceno final-Holoceno en la Región Pampeana (Argentina). ArchaeoZoologia XII: Zooarchaeology of South America. G. Mengoñi Goñalons (ed.). Bar International Series 1298: 81-98. 
Martínez, G, A. Sangrando y L. Stoessel. 2005. Sitio El Tigre (pdo. de Patagones, pcia. de Buenos Aires, Argentina): evidencias de peces en el curso inferior del río Colorado e implicaciones para los sistemas de subsistencia. Magallania 33 (2). En prensa.

Mazzanti, D.L. 1993. El período tardío en la arqueología bonaerense. En Mandrini, R. y A. Reguera (comps.); Huellas en la Tierra: 31-44. Tandil, IEHS.

Mazzanti, D. y C. Quintana. 2001. Cueva Tixi: cazadores y recolectores de las sierras de Tandilia Oriental. 1 Geología, Paleontología y Zooarqueología. Laboratorio de Arqueología, UNMdP, Publicación Especial 1. Mar del Plata.

Meggers, B. 1971. Amazonia: Man and Culture in a Counterfeit Paradise. Aldine, Chicago.

Menghín, O. F. y M. Bórmida. 1950. Investigaciones prehistóricas en cuevas de Tandilia (Provincia de Buenos Aires). Runa 5: 1-36.

Oliva, F; J. Moirano y M. Saghesi. 1991 ${ }^{\mathrm{a}}$. Estado de las investigaciones arqueológicas en el sitio Laguna de Puán 1. Boletín del Centro 2:127-138.

Oliva, F. A. Gil, y M. Roa. 1991b. Recientes investigaciones en el Sitio San Martín 1 (BU/PU/5). Partido de Puán, provincia de Buenos Aires. Shincal 3 (3) 135-139.

Orquera, L. 1987. Advances in the Archaeology of the Pampa and Patagonia. Journal of World Archaeology 1(4):333-464.

Osterrieth, M. y G. Tassara. 2005. Silicofitolítos en artefactos de molienda de sitios arqueológicos del área Interserrana, Buenos Aires. Trabajo Presentado en III Encuentro de Investigaciones Fitoliticas del Cono Sur, Tafi del Valle, Tucumán.

Outes, F. 1926. Noticias sobre el resultado de mis investigaciones antropológicas en la extremidad sudeste de la Provincia de Buenos Aires. Physis 8: 387-390.

Outes, F. y C. Bruch. 1910. Los aborígenes argentinos. Buenos Aires, Estrada.

Palavecino, E. 1948. Áreas y capas culturales en el territorio Argentino, Gaea, Vol. 8, pp. 447-523. Buenos Aires.

Paleo, M. C., Páez, M. y M. Pérez Meroni. 2002. Condiciones ambientales y ocupaciones humanas durante el Holoceno Tardío en el litoral fluvial bonaerense. En Del Mar a los Salitrales. Diez mil años de Historia Pampeana en el U,bral del tercer Milenio. Mazzanti, D., M. Berón y F. Oliva (eds.); pp. 365-376. Mar del Plata, Universidad Nacional de Mar del Plata.

Paleo, M. C. y M. Pérez Meroni. 2001. Primeros resultados del sitio "Las Marias", pdo. de Magdalena, pcia. de Buenos Aires. Trabajo presentado en el XIV Congreso Nacional de Arqueología Argentina, Rosario 17 al 21 de Sepriembre de 2001

Paleo, M. C. y M. Pérez Meroni. 2004. Problemáticas vinculadas a las estrategias de subsistencia de la Localidad Arqueológica Barrio San Clemente. En La Región Pampeana- su pasado arqueológico-, C. Gradín y F.Oliva (eds.), pp. 311-320. Universidad Nacional de Rosario. Laborde Editor.

Parodi, L. 1940. Los bosques naturales de la provincia de Buenos Aires. Anales de la Academia Nacional de Ciencias de Buenos Aires, VII: 79-90.

Parodi, L. 1947. La estepa pampeana. En La Vegetación Argentina, Tomo VIII: 143-207. Buenos Aires.

Podgorny, I. 1994. Arqueología y Educación: la inclusión de la arqueología pampeana en la educación Argentina. Tesis Doctoral inédita, Universidad Nacional de la Plata, Facultad de Ciencias Naturales.

Podgorny, I. 1999. De la antigüedad del hombre en el Plata a la distribución de las antigüedades en el mapa: los criterios de la organización de las colecciones antropológicas del Museo de La Plata entre 1897 y 1930. História,Ciências, Saúd, VI (1): 81-100. 
Politis, G.. 1984. Arqueología del Área Interserrana Bonaerense. Tesis Doctoral inédita, 2 vol. Facultad de Ciencias Naturales y Museo, Universidad Nacional de La Plata. Inédita.

Politis, G.. 1988. Cambios climáticos y estrategias adaptativas en el Este de la Región Pampeana. Actas del $45^{\circ}$ Congreso Internacional de Americanistas. Bogotá, 3:263-278

Politis, G.. 2000. Los cazadores de la llanura. Nueva Historia Argentina. Los pueblos originarios y la conquista: 61-103. Buenos Aires., Sudamericana. En prensa. Nukak. Hunter-gatherers of the Amazonian Rain forest. An ethnoarchaelogical perspective. University College London Press. Inglaterra.

Politis G, y D. C. León. 2005. Patrones adaptativos de los cazadores-recolectores-pescadores de la margen occidental del Paraná inferior-Plata. Libro de Resúmenes del Primer Encuentro de Discusión de Arqueología del Noroeste Argentino., pp 19. Santa Fé.

Politis, G. y P. Madrid. 2001. Arqueología Pampeana: Estado Actual y Perspectiva. En: Historia Argentina Prehispánica. Tomo II. pp. 737-814. Editorial Brujas.

Politis, G. y M. Salemme. 1990. Prehispanic mamad exploitation and the hunting strategies in Eastern Pampa Subregion of Argentina. En: Hunters of The Recent Past L. Davis y B. Reeves (eds.), pp. 352-372. One World Archaeology, 15. Unwin-Hyman. London,

Ringuelet, R. 1955. Panorama Zoogeográfico de la Provincia de Buenos Aires. Notas del Museo de La Plata 18 (156), 12 pp. Facultad de Ciencias Naturales y Museo de La Plata. UNLP, La Plata.

Ringuelet, R. y R. H. Aramburu. 1957. Enumeración sistemática de los vertebrados de la provincia de Buenos Aires. Ministerio de Asuntos Agrarios. La Plata pp.119-194.

Rolleri, E. 1975. Provincias geológicas bonaerenses. VI Congreso Geológico Argentino. Relatorio. Geología de la Provincia de Buenos Aires: 29-53. Buenos Aires.

Saleme, M. 1987. Paleoetnozoología del sector bonaerense de la región pampeana con especial atención a los mamíferos. Tesis Doctoral. Facultad de Ciencias Naturales y Museo. Universidad Nacional de la Plata.

Serrano, A. 1955. Los pueblos y culturas indígenas del Litoral. Santa Fé, El Litoral.

Soriano, A. 1979. Distribution of grasses and grasslands in South America. En: M.Numata (Ed.), Ecology of Grasslands and Bamboolands in the World.VEB Gustav Fischer, Jena, pp. 84-91.

Soriano A., León R. J. C., Sala O. E., Deregibus V. A., Cauhépé M.A., Scaglia O.A., Velázquez C. A. y J. H. Lemcoff. 1992. Río de La Plata Grasslands. En: R. Coupland (ed.) Natural Garsslands. Introduction and Western Hemisphere, pp. 367-407. Elsevier

Steward, J. 1949. Culture Areas of the Tropical Forests. En: Steward, J. (ed.) Handbook of South American Indians 3:883-900. Washington, Smithsonian Institution.

Steward, J. 1955. Theory of culture change. The methodology of multilinear evolution. University of Illinois Press.

Tapia, A. y J. Charlín. 2004. Actividades de molienda y pulido en la tolderías ranquelinas del caldenar pampeano. En: Aproximaciones Contemporáneas a la Arqueología Pampeana. Perspectivas teóricas, metodológicas, analíticas y casos de estudio. G. Martínez, M. Gutiérrez, R. Curtoni, M. Berón y P. Madrid (eds.) pp. 363-386. Publicación de la Facultad de Ciencias Sociales. UNCPBA.

Torres, L. M. 1917. Los tiempos prehistóricos y protohistóricos. En Manual de la historia de la civilización argentina. R Carbía (ed.). Biblioteca de la Asociación Nacional del Profesorado. Buenos Aires.

Torres, L. M. 1935. Los tiempos prehistóricos y protohistóricos en la República Argentina. $2^{\mathrm{da}}$ ed. corregida y actualizada. Buenos Aires, Kapeluz.

Willey, G. 1944. The Archaeology of the Greater Pampa in Handbook of South American Indians, J. H. Steward, ed., Vol. 1, pp. 25-46, Bureau of American Ethnology. Bulletin 143. Smithsonian 
Institution. Washington.

Wright. P. 2005. Los indígenas del Chaco argentino. En X. Martíni (ed) Aborígenes del Gran Chaco. Fotografias de Grete Stern 1958-1964, pp. 24-33. Fundación Antorchas, Buenos Aires.

Zucol, A. F. y M. Bonomo. 2005. Estudios etnobotánicos del sitio arqueológico Nutria Manza 1 (Partido de General Alvarado, Provincia de Buenos Aires): II Análisis fitolíticos comparativos de artefactos de molienda. Libro de Resúmenes del III Encuentro de Investigaciones Fitolíticas del Cono Sur, pp 19-21. Taif del Valle, Tucumán.

\title{
Resumen
}

En este artículo se discute el concepto de región pampeana como una unidad espacial y cultural en el análisis arqueológico y se analiza la validez y la operatividad que mantiene actualmente. Esta región fue usada como unidad de análisis en arqueología, pero fue definida con diferentes criterios y grados de resolución. En este trabajo se examinan y discuten estos criterios y su validez en la actualidad, ya que el uso de información tanto ecológica como cultural, provocó ciertas incongruencias en la forma en que se ha hecho operativo el establecimiento y la definición de los límites de la región pampeana.

En suma, parece claro que lo que llamamos actualmente región pampeana en la arqueología sudamericana es una unidad espacial que no tiene una correspondencia ecológica ni cultural. Teniendo esto en cuenta, se debe concluir que el uso de la región pampeana como unidad de análisis, tal cual está definida actualmente, se basa en tradiciones de investigación y en cierto consenso contemporáneo más que en características ecológicas o arqueológicas distintivas.

$<$ Pampa $><$ región pampeana $><$ Arqueología $>$

\begin{abstract}
In this paper, the concept of the Pampean region as a spatial and cultural unit for archaeological analysis is discussed. This region has been used in archaeology as an analytical unit but it has been defined based on different criteria and scales of resolution. These criteria will be examined in this paper, as well as their validity for current archaeological analysis, since the use of ecological and cultural data generated some incongruence in the way the boundaries of the Pampean region have been defined.

Presently, it seems clear that what we consider the Pampean region in South American archaeology is a spatial unit which does not correspond to an ecological or cultural unit. Taking this into account, we must conclude that the use of the concept of the Pampean region as a unit is based mainly on research tradition and a consensus among archaeologists rather than on its intrinsic ecological and archaeological characteristics.
\end{abstract}

$<$ Pampa $><$ pampeana region $><$ Archelogy $>$ 